\title{
Noninvasive detection of acute renal allograft rejection by measurement of soluble Tim-3 in urine
}

\author{
DAJIN CHEN, WENHAN PENG, HONG JIANG, HAO YANG, \\ JIANYONG WU, HUIPING WANG and JIANGHUA CHEN
}

\begin{abstract}
Kidney Disease Center, The First Affiliated Hospital, College of Medicine, Zhejiang University, Hangzhou, Zhejiang 310003, P.R. China
\end{abstract}

Received March 16, 2016; Accepted March 9, 2017

DOI: $10.3892 / \mathrm{mmr} .2017 .6670$

\begin{abstract}
The purpose of the present study was to assess whether urinary soluble T-cell immunoglobulin and mucin domain-containing protein 3 (sTim-3) could be adopted as a novel non-invasive biomarker for acute rejection (AR) following renal transplantation. A total of 156 patients were enrolled between January 2006 and December 2009, comprising 49 patients with biopsy-proven AR, 58 patients with stable grafts and no abnormal histological findings (NO-AR), 10 patients with subclinical rejection (SCR) in protocol biopsies, 10 patients with acute tubular necrosis (ATN) and 29 patients with chronic allograft nephropathy (CAN). Additionally, urine samples from 40 healthy individuals were also collected as controls. The urinary concentration of sTim-3 was determined by ELISA in the 156 renal allograft recipients and 40 healthy controls. Compared with NO-AR and healthy controls, patients with AR excreted urinary sTim-3 at a significantly higher level $(4,356 \pm 440.4,95 \%$ CI: 3,473-5,242 $\mathrm{ng} / \mathrm{mmol}$ creatinine). Likewise, patients with ATN exhibited a significantly lower level of urinary sTim-3 $(2,060 \pm 217,95 \%$ CI: $1,679-2,680 \mathrm{ng} / \mathrm{mmol}$ creatinine) than patients with AR. The discriminatory value was measured by the area under the receiver operating characteristic curve (ROC), which had a value of 0.88 (95\% CI: 0.809-0.951), demonstrating that sTim-3 was a suitable marker for the diagnosis of AR. At a cut-off point of $1,836 \mathrm{ng} / \mathrm{mmol}$ creatinine, the sensitivity was $89.8 \%$ and the specificity was $82.8 \%(\mathrm{P}<0.001)$. Amongst the patients with AR, patients with steroid-resistant acute rejection $(n=31)$ had significantly higher urinary sTim-3 concentrations than patients with steroid-sensitive acute rejection $(\mathrm{n}=18 ; 5,548 \pm 613.5,95 \% \mathrm{CI}: 4,287-6,809 \mathrm{ng} / \mathrm{mmol}$
\end{abstract}

Correspondence to: Professor Jianghua Chen, Kidney Disease Center, The First Affiliated Hospital, College of Medicine, Zhejiang University, 79 Qingchun Road, Hangzhou, Zhejiang 310003, P.R. China

E-mail: chenjianghua1212@126.com

Key words: kidney transplantation, acute rejection, soluble T-cell immunoglobulin and mucin domain-containing protein 3 , acute tubular necrosis creatinine vs. $2,653 \pm 391.7,95 \%$ CI: $1,830-3,476 \mathrm{ng} / \mathrm{mmol}$ creatinine; $\mathrm{P}=0.0002)$. No significant difference in urinary sTim-3 was found between patients with AR and CAN $(3,920 \pm 543.5,95 \%$ CI: $3,473-5,242 \mathrm{ng} / \mathrm{mmol}$ creatinine), and a significantly higher level of Tim-3 was excreted by patients with CAN compared with patients with NO-AR and healthy controls $(\mathrm{P}<0.001)$. The present study, therefore, suggests that urinary sTim-3 may be used as a valuable non-invasive biomarker for the detection of AR. In addition, urinary sTim-3 levels were demonstrated to be associated with the response to anti-rejection therapy. The results of the present study may provide support future research into the screening of novel immune suppressants.

\section{Introduction}

Renal transplantation currently represents the best treatment option for most patients with end-stage organ failure, due to improved cardiovascular and mortality outcomes and quality of life compared with dialysis $(1,2)$. Nevertheless, despite advances in immunosuppression, almost 35\% of renal transplant recipients have an episode of acute rejection (AR) in the first year following transplantation (3). The presence of AR results in a 20\% reduction in the first year survival rate (3). The intensity of the rejection and the therapeutic response may have a direct impact on the long-term outcome of the graft. Early diagnosis is important in order to allow appropriate treatment to be initiated (4). Histopathological examination of renal biopsy tissue is regarded as the gold standard for diagnosing acute rejection; however, due to an inability to repeatedly obtain samples within short time frames to eliminate concurrent complications, the development of a noninvasive method as a substitute for histopathological examination is imperative (5). A noninvasive test that could be used for monitoring acute rejection would, therefore, be of considerable value.

Approximately $70 \%$ of urinary proteins are generated in the kidney, with the remainder generated in plasma $(6,7)$, therefore, small changes in urinary protein excretion may reflect kidney state; previous studies have consistently revealed significant differences between transplant recipients with acute rejection and recipients with stable graft functions (8-10). In addition, several urinary proteins and chemokines have been identified as biomarkers of acute rejection following renal 
transplantation, including increased levels of urinary fractalkine, vascular endothelial growth factor, inducible protein-10 or monokine induced by interferon $\gamma(11,12)$.

Acute allograft rejection is predominantly a Th1-driven cellular response, mediated by infiltrating lymphocytes that produce specific cytokines and cytotoxic effector molecules, culminating in tissue injury and ultimately graft dysfunction (13). Recently, a new molecule has been described as a hallmark of Th1-specific differentiated cells, T-cell immunoglobulin and mucin domain-containing protein 3 (Tim-3; officially known as hepatitis A virus cellular receptor 2) (14). Tim-3 is a type I membrane protein that is preferentially expressed on terminal differentiated Thl cells (15). It exists as either a membrane bound form (fTim-3) or in soluble form (sTim-3) (16). Along with the other Tim family members, Tim-3 is involved in several immune process, including the development of autoimmune diseases, tolerance induction and the regulation of Th1 immune responses $(17,18)$. To the best of our knowledge, there are currently no data concerning levels of urinary sTim-3 in acute renal allograft rejection.

In the present study, urinary sTim-3 excretion at the time of acute rejection was evaluated and whether urinary sTim-3 levels were associated with a response to anti-rejection treatment. In addition, the value of this non-invasive method for the assessment of renal allograft rejection was assessed.

\section{Materials and methods}

Patients and sample collection. Urine samples from 156 patients who received renal transplants between June 2006 and December 2009 were examined in our center. A total of 49 patients had biopsy-confirmed phenotypes of acute rejection (AR) with an elevated serum creatinine level of $\geq 25 \%$ above baseline within 6 months of transplant, while 58 patients had stable grafts and no abnormal histological findings (NO-AR) in protocol biopsies performed 2-3 months following transplantation. Fresh first-morning mid-flow urine samples from patients were collected every 2 weeks during the first 2 months following transplantation. Urine samples were similarly collected from the 10 patients with biopsy-proven acute tubular necrosis (ATN), 29 patients with chronic allograft nephropathy (CAN) and 10 patients with subclinical rejection (SCR). Urine samples were not collected on the day of biopsy. All subjects received primary grafts from deceased donors. Detailed demographic characteristics of these groups are summarized in Table I, with no significant differences identified between groups ( $\mathrm{P}>0.05$; Table I). Patients with signs of infection or malignant tumor were excluded from the study. Urine samples were also collected from 40 healthy individuals as controls (average age: $39.6 \pm 6.8$ years; male/female: $24 / 16$ ). Normal controls were recruited from the medical examination center of our center. The study was approved by the Ethics Committee of The First Affiliated Hospital of College of Medicine of Zhejiang University (Zhejiang, China) in accordance with the Declaration of Helsinki, and all of the study participants provided written informed consent.

Details of immune suppressive protocols used in Chinese renal allograft recipients have been previously reported by this group (19). All subjects who were recruited to participate in the present study were receiving a combination of three immunosuppressive drugs at the time of transplantation, composed of a calcineurin inhibitor (tacrolimus or cyclosporine, tacrolimus: trough level 5-10 $\mathrm{ng} / \mathrm{ml}$, or cyclosporin: Trough level 200-300 ng/ml for six months following the transplant), prednisone (in tapering doses from 80-10 mg/day within the first month after transplant), and azathioprine or mycophenolatemofetil. A3 day course of intravenous methylprednisolone $(6 \mathrm{mg} / \mathrm{kg})$ was used as anti-rejection therapy following clinical and biopsy-proven diagnosis of acute rejection. Steroid-resistant acute rejection (SRAR) was defined as lack of response to steroid treatment (graft function had no improvement or worsened) and was treated with OKT3 (5 mg/day) for 5-7 days. In addition, plasma exchange therapy was performed in patients diagnosed with humoral rejection. A single experienced renal pathologist who was unaware of the results of the study used Banff 97 classification $(20,21)$ to evaluate all biopsy specimens.

Fresh urine samples were immediately centrifuged for $10 \mathrm{~min}$ at $1,600 \mathrm{x} \mathrm{g}$ at $4^{\circ} \mathrm{C}$, then the supernatant was aliquoted and stored at $-80^{\circ} \mathrm{C}$ until required. Urinary creatinine and protein were measured for the purpose of calibration; sTim-3 levels determined by ELISA were expressed per millimole of urinary creatinine to correct for differences in urine concentration.

Determination of sTim-3 in urine by ELISA. sTim-3 was measured in urine samples using a commercial human sTim-3 ELISA kit (catalog no. T133-90; Groundwork Biotechnology Diagnosticate, Ltd., San Diego, CA, USA). Undiluted urine samples were tested in duplicate according to the manufacturer's protocol.

Statistical analysis. Statistical analysis was performed using SPSS version 16.0 (SPSS, Inc., Chicago, IL, USA). Parameters between groups were compared using the Mann-Whitney or Kruskal-Wallis test and post hoc tests for nonparametric continuous data. To measure the sensitivity and specificity of urinary sTim-3 in distinguishing between AR and NO-AR patients, a conventional receiver operating characteristic (ROC) curve was generated. ROC curves were also used to determine the sensitivities and specificities for sTim-3 measurements to diagnose SCR and predict the outcome following acute rejection. The diagnostic and predictive value of this model was investigated by the area under the ROC curve. Youden's index, defined as sensitivity + specificity-1, was used for the computation of the diagnostic threshold. Results were expressed in the text as mean \pm standard error of the mean unless otherwise stated. $\mathrm{P}<0.05$ was considered to indicate a statistically significant difference.

\section{Results}

A total of 156 patients, enrolled between January 2006 and December 2009 in our single-center, were studied, including 49 with biopsy-proven AR. Among the 49 patients with AR, 37 were diagnosed as cellular rejection and 12 were humoral rejection according to antibody-mediated rejection criteria. For 37 patients with cellular rejection, 20, 14 and 3 were diagnosed as grade I, grade II and grade III, respectively. Of the remaining patients, 58 patients had NO-AR, 10 patients 
Table I. Demographic characteristics of patients with renal transplants.

\begin{tabular}{|c|c|c|c|c|c|}
\hline Variable & AR $(n=49)$ & $\operatorname{ATN}(n=10)$ & CAN (n=29) & $\operatorname{SCR}(n=10)$ & NO-AR $(n=58)$ \\
\hline Mean age (years) & $36.9 \pm 9.6$ & $37.3 \pm 5.8$ & $45.8 \pm 9.5$ & $37.3 \pm 10$ & $39.8 \pm 10.1$ \\
\hline \multicolumn{6}{|l|}{$\operatorname{Sex},[\mathrm{n}(\%)]$} \\
\hline Male & $34(69.4 \%)$ & $7(70 \%)$ & $20(68.9 \%)$ & $6(66.7 \%)$ & $36(62.1 \%)$ \\
\hline Female & $15(30.6 \%)$ & $3(30 \%)$ & $9(31.1 \%)$ & $4(33.3 \%)$ & $22(37.9 \%)$ \\
\hline \multicolumn{6}{|l|}{ Cause of ESRD [n(\%)] } \\
\hline Glomerulonephritis & $38(77.6 \%)$ & $8(80 \%)$ & $24(82.7 \%)$ & $8(80 \%)$ & $44(75.9 \%)$ \\
\hline Hypertension & $2(4.1 \%)$ & 0 & $1(3.4 \%)$ & 0 & $2(3.4 \%)$ \\
\hline Obstructive uropathy & $1(2.1 \%)$ & 0 & 0 & 0 & $1(1.7 \%)$ \\
\hline Diabetes & $4(8.1 \%)$ & $1(10 \%)$ & $2(6.9 \%)$ & $1(10 \%)$ & $4(6.8 \%)$ \\
\hline Others & $4(8.1 \%)$ & $1(10 \%)$ & $2(7 \%)$ & $1(10 \%)$ & $7(12.1 \%)$ \\
\hline Dialysis time (months) & $6.5 \pm 4.1$ & $5.3 \pm 2.8$ & $6.3 \pm 4.7$ & $5.5 \pm 6.2$ & $6.9 \pm 7.1$ \\
\hline HLA mismatch & $3.6 \pm 1.3$ & $3.5 \pm 1.2$ & $3.9 \pm 1.5$ & $3.3 \pm 1.4$ & $3.2 \pm 1.3$ \\
\hline Cold ischaemia (h) & $8.3 \pm 1.9$ & $8.6 \pm 2.0$ & $8.5 \pm 2.1$ & $8.4 \pm 1.8$ & $8.1 \pm 1.6$ \\
\hline \multicolumn{6}{|c|}{ Panel reactive antibody $[\mathrm{n}(\%)]$} \\
\hline$<10 \%$ & $44(89.8 \%)$ & $9(90 \%)$ & $26(89.7 \%)$ & $9(90 \%)$ & $54(93.1 \%)$ \\
\hline$>10 \%$ & $5(10.2 \%)$ & $1(10 \%)$ & $3(10.3 \%)$ & $1(10 \%)$ & $4(6.9 \%)$ \\
\hline
\end{tabular}

AR, acute rejection; ATN, acute tubular necrosis; CAN, chronic allograft nephropathy; SCR, subclinical rejection; NO-AR, no acute rejection; ESRD, end-stage renal disease; HLA, human leucocyte antigen. Data are presented as the mean \pm standard deviation.

had SCR in protocol biopsy, 10 patients had biopsy-proven ATN and 29 patients had biopsy-proven CAN. Additionally, urine samples from 40 healthy individuals were collected as controls.

Urinary sTIM-3 in patients with stable renal function. In the 58NO-AR patients, the level of urinary sTim-3 did not change significantly during the first 8 weeks following transplantation, with a value of $1,732 \pm 182 \mathrm{ng} / \mathrm{mmol}$ creatinine at 2 weeks, $1,504 \pm 154.1 \mathrm{ng} / \mathrm{mmol}$ creatinine at 4 weeks, $1,515 \pm 87.2 \mathrm{ng} / \mathrm{mmol}$ creatinine at 6 weeks and $1,415 \pm 144.4 \mathrm{ng} / \mathrm{mmol}$ creatinine at 8 weeks (Fig. 1).

Urinary STIM-3 in patients with acute renal allograftrejection. All patients diagnosed with AR $(n=49)$ were treated with intravenous methylprednisolone. Among them, 18 patients with reversible creatinine increases were classified as SSAR, while 31 patients showing no improvement following steroids were classified as SRAR. Patients with SRAR were further treated with OKT3, plasma exchange or both. A total of 47 patients were successfully controlled. Anti-rejection treatment appeared to be unsuccessful in 2 patients. In these cases, graft function deteriorated rapidly, with grafts failing within 3 months of the transplant procedure.

A total of 31 of the 49 patients with AR also had urine samples taken before or after the occurrence of AR. The concentration of urinary sTim-3 in patients during the period of $\operatorname{AR}(4,221 \pm 529.6,95 \% \mathrm{CI}$ : 3,123-5,266 ng/mmol creatinine) was significantly higher than during stable renal function, both before the occurrence of $\mathrm{AR}(1,507 \pm 229.3,95 \% \mathrm{CI}$ : 1,239-2,065 ng/mmol creatinine; $\mathrm{P}<0.001)$ and after AR reversion $(1,493 \pm 210,95 \% \mathrm{CI}: 1,267-1,960 \mathrm{ng} / \mathrm{mmol}$ creatinine; $\mathrm{P}<0.001)$.

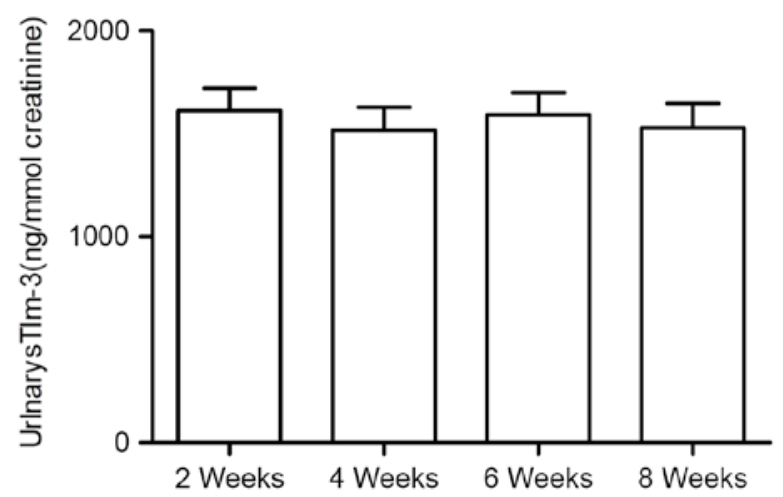

Figure 1. Levels of urinary sTim-3during the first 8 weeks following transplantation in the 58 patients without acute rejection and with stable renal function. Data are presented as the mean \pm standard error of the mean. No significant differences in urinary sTim-3 were observed. sTim-3, soluble T-cell immunoglobulin and mucin domain-containing protein 3 .

Urinary sTim-3 is an indicator of acute renal allograft rejection. Compared with those without rejection (patients with NO-AR, ATN or healthy controls), patients with AR had significantly higher levels of urinary sTim-3 (Fig. 2): 4,356 \pm 440.4 , 95\% CI: $3,473-5,242 \mathrm{ng} / \mathrm{mmol}$ creatinine in patients with AR; $1,430 \pm 106.2,95 \% \mathrm{CI}: 1,118-1,548 \mathrm{ng} / \mathrm{mmol}$ creatinine in

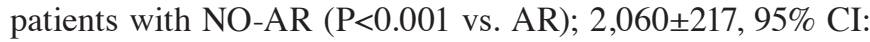
$1,679-2,680 \mathrm{ng} / \mathrm{mmol}$ creatinine in patients with ATN $(\mathrm{P}=0.02$ vs. AR); and 1,269 $\pm 99.3,95 \%$ CI: $1,068-1,469 \mathrm{ng} / \mathrm{mmol}$ creatinine in healthy controls ( $\mathrm{P}<0.001$ vs. AR).Urinary sTim-3levels in patients with AR were also higher than in patients with CAN $(3,920 \pm 543.5,95 \%$ CI: 3,473-5,242 ng/mmol creatinine), however, the difference was not statistically significant $(\mathrm{P}=0.058$ vs. AR; Fig. 2). Urinary sTim-3 concentrations in 


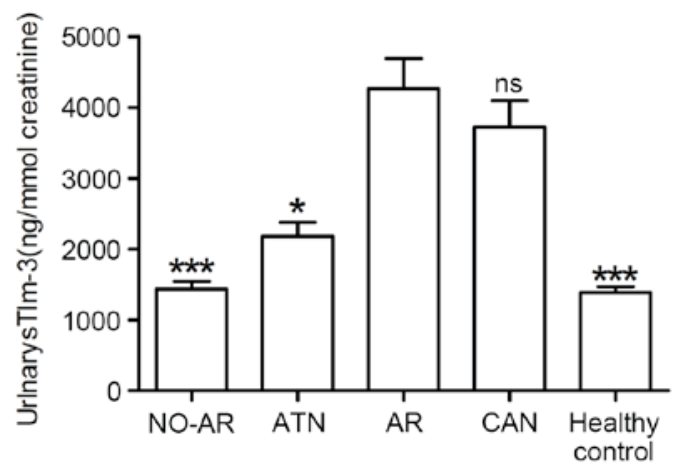

Figure 2. Average concentration of urinary sTim-3 in renal transplant patients with NO-AR, AR, ATN or CAN, and healthy controls. ${ }^{\text {ns }} \mathrm{P}>0.05,{ }^{*} \mathrm{P}<0.05$ and ${ }^{* * *} \mathrm{P}<0.001$ vs. AR. sTim-3, soluble T-cell immunoglobulin and mucin domain-containing protein 3; NO-AR, no acute rejection; AR, acute rejection; ATN, acute tubular necrosis; CAN, chronic allograft nephropathy.

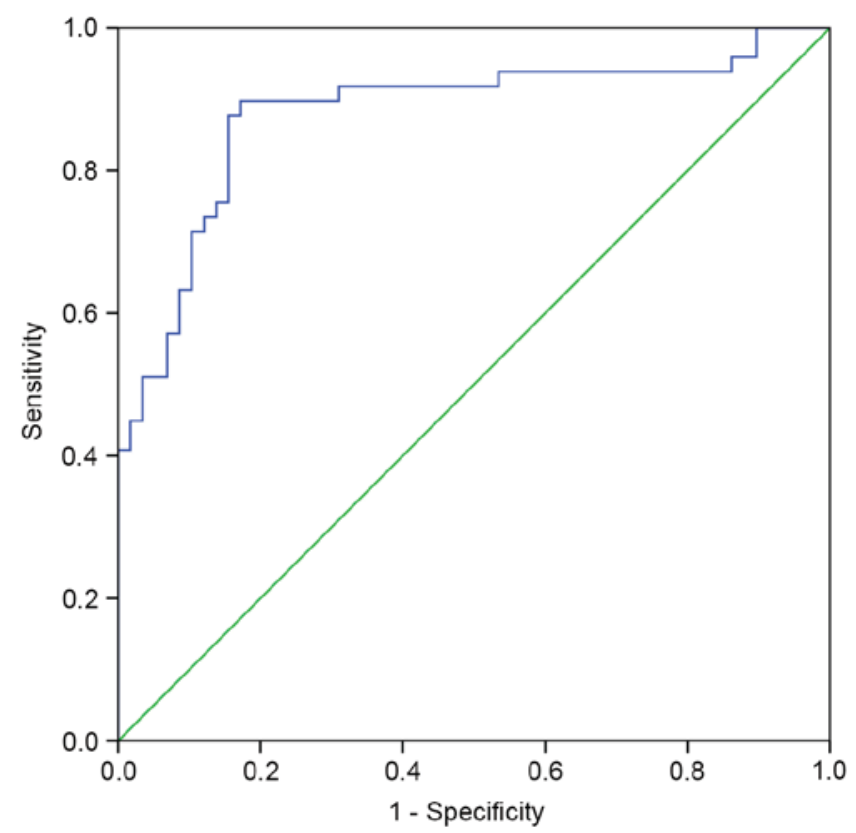

Figure 3. ROC curve analysis of sTim-3 as a marker for diagnosis of acute rejection. The area under the ROC curve was 0.874 (95\% CI:0.80-0.948; $\mathrm{P}<0.001$ ), which demonstrated that sTim-3 was a suitable marker for the diagnosis of acute rejection. ROC, receiver operating characteristic; sTim-3, soluble T-cell immunoglobulin and mucin domain-containing protein 3.

patients with NO-AR and in the 40 healthy controls were extremely similar, both remaining at relatively low levels, as depicted in Fig. 2.

A ROC curve was performed to determine the discriminatory power of sTim-3 levels for diagnosis of acute rejection (Fig. 3). The area under ROC curve was 0.88 (95\% CI: 0.809-0.951). The optimal cutoff level for sTim-3 was $1,836 \mathrm{ng} / \mathrm{mmol}$ creatinine, with a sensitivity and specificity of 89.8 and $82.8 \%$, respectively $(\mathrm{P}<0.001)$. When the cutoff level was set at $2,764 \mathrm{ng} / \mathrm{mmol}$ creatinine, the corresponding specificity was $91.4 \%$.

Levels of urinary sTim-3 in cellular and humoral rejection. Among the 49 patients with AR, 37 were diagnosed as cellular rejection and 12 were humoral rejection according

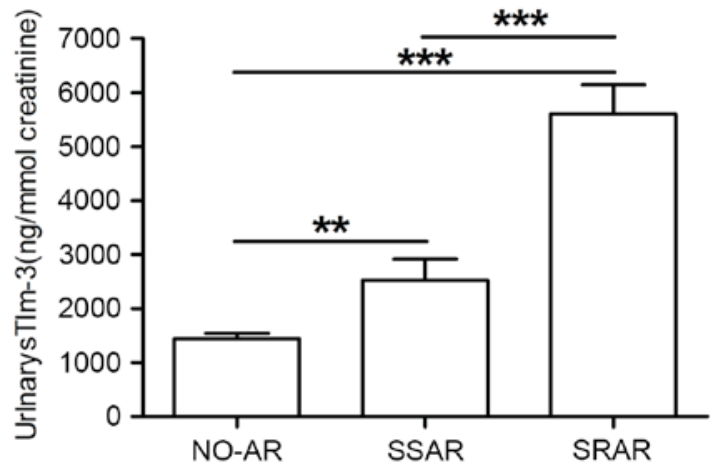

Figure 4. Average concentration of urinary sTim-3 in renal transplant patients with SRAR compared with urinary sTim-3 in patients with SSAR and NO-AR. ${ }^{* *} \mathrm{P}<0.01$ and ${ }^{* * *} \mathrm{P}<0.001$, with comparisons indicated by lines sTim-3, soluble T-cell immunoglobulin and mucin domain-containing protein 3; SRAR, steroid-resistant acute rejection; SSAR, steroid-sensitive acute rejection; NO-AR, no acute rejection.

to antibody-mediated rejection criteria. Patients with cellular rejection excreted sTim-3 (4,010 $\pm 490.7,95 \%$ CI: 3,010-4,985 $\mathrm{ng} / \mathrm{mmol}$ creatinine) less than those with humoral rejection $(5,091 \pm 961.5 \mathrm{ng} / \mathrm{mmol}$ creatinine, $95 \% \mathrm{CI}$ : 3,012-7,210 $\mathrm{ng} / \mathrm{mmol}$ creatinine), but this effect was not statistically significant $(\mathrm{P}=0.15)$.

High levels of urinary-3 are predictive of SRAR and graft loss. The 31 patients with SRAR had significantly greater urinary sTim-3 concentrations $(5,660 \pm 616.5$, $95 \%$ CI: $4,387-6,890 \mathrm{ng} / \mathrm{mmol}$ creatinine) than the 18 patients with SSAR $(2,753 \pm 386.7,95 \% \mathrm{CI}: 1,930-3,576 \mathrm{ng} / \mathrm{mmol}$ creatinine) and 58 patients with NO-AR ( $\mathrm{P}<0.001$; Fig. 4). Patients with SSAR excreted significantly more urinarys TIM-3 than NO-AR patients ( $\mathrm{P}=0.009$; Fig. 4). The ROC curve demonstrated the sensitivity and specificity of various cutoff levels for urinarys Tim-3 to predict the incidence of SRAR (Fig. 5). The area under the ROC curve was 0.86 (95\% CI: 0.744-0.976, $\mathrm{P}<0.001)$. The cutoff point that optimized the combined sensitivity and specificity for sTim-3 was 3,242.9 ng/mmol creatinine. At this threshold, the sensitivity was $83.9 \%$ and the specificity was $88.9 \%(\mathrm{P}<0.001)$.

The 2 patients with graft loss appeared to have higher urinary sTim-3 concentrations than the 47 patients with reversible acute rejection $(6,496 \pm 1,488,95 \% \mathrm{CI}$ : 2,981-10,065 ng/mmol creatinine vs. 4,252 $\pm 445.1,95 \% \mathrm{CI}$ : 3,356-5,249 $\mathrm{ng} / \mathrm{mmol}$ creatinine), but the difference between these two groups was not statistically significant $(\mathrm{P}=0.17)$. A negative association between urinary sTim-3 concentration and estimated glomerular filtration rate (eGFR) was also identified (Fig. 6). As demonstrated in Fig. 6, patients with a high average urinary sTim- 3 concentration within 2 months of transplantation $(>4,000 \mathrm{ng} / \mathrm{mmol}$ creatinine; $\mathrm{n}=99)$ had a significantly lower eGFR than the group with low average sTim-3 levels $(<2,000 \mathrm{ng} / \mathrm{mmol}$ creatinine; $\mathrm{n}=57)$ : 3 months after transplantation, eGFR in the group with lower average sTim-3 was $80.2 \pm 2.2 \mathrm{ml} / \mathrm{min} 1.73 \mathrm{~m}^{2}$ vs. $59.4 \pm 5.9 \mathrm{ml} / \mathrm{min}$ $1.73 \mathrm{~m}^{2}$ in the group with higher sTim-3 levels $(\mathrm{P}<0.001)$; $85.2 \pm 2.6 \mathrm{ml} / \mathrm{min} 1.73 \mathrm{~m}^{2}$ in the group with lower average sTim-3 vs. $60.9 \pm 8.6 \mathrm{ml} / \mathrm{min} 1.73 \mathrm{~m}^{2}$ in the group with higher sTim-3 levels 6 months after transplantation $(\mathrm{P}<0.001)$; 


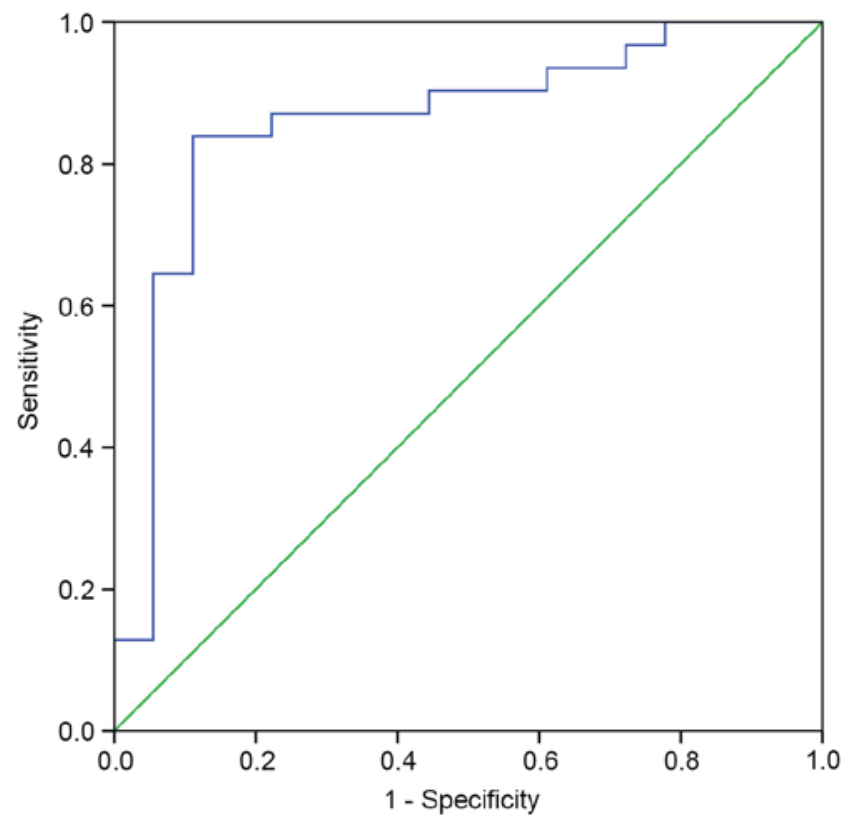

Figure 5. ROC curve analysis of urinary sTim-3 as a marker for the diagnosis of SRAR. The area under the ROC curve was 0.77 (95\% CI: 0.66-0.88; $\mathrm{P}<0.001$ ), which demonstrated that high levels of urinary sTim-3 are predictive of SRAR. ROC, receiver operating characteristic; sTim-3, soluble T-cell immunoglobulin and mucin domain-containing protein 3; SRAR, steroid-resistant acute rejection.

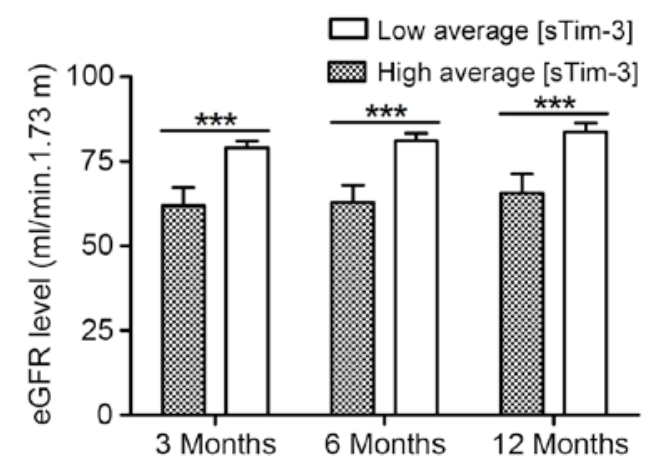

Figure 6. eGFR in patients with high $(>4,000 \mathrm{ng} / \mathrm{mmol}$ creatinine; $\mathrm{n}=99)$ and low $(<2,000 \mathrm{ng} / \mathrm{mmol}$ creatinine; $\mathrm{n}=57)$ average urinary sTim-3 concentrations within 2 months of transplantation. ${ }^{* * * *} \mathrm{P}<0.001$, with comparisons indicated by lines. eGFR, estimated glomerular filtration rate; sTim-3, soluble T-cell immunoglobulin and mucin domain-containing protein 3.

and $86.6 \pm 3.6 \mathrm{ml} / \mathrm{min} 1.73 \mathrm{~m}^{2}$ in the group with lower average sTim-3 vs. $60.9 \pm 8.6 \mathrm{ml} / \mathrm{min} 1.73 \mathrm{~m}^{2}$ in the group with higher sTim-3 levels 12 months after transplantation $(\mathrm{P}<0.001)$.

Urinary sTim-3 is an indicator of subclinical rejection. A total of 10 patients were diagnosed with subclinical rejection (SCR) in protocol biopsy according to Banff 97 classification; urinary sTim-3 levels were determined to be suitable as an indicator in these patients too. Patients with SCR excreted urinary sTim-3 at a significantly higher level $(3,783 \pm 760.9$, 95\% CI: $2,087-5,478 \mathrm{ng} / \mathrm{mmol}$ creatinine) than patients with NO-AR $(1,430 \pm 106.2,95 \% \mathrm{CI}: 1,118-1,548 \mathrm{ng} / \mathrm{mmol}$ creatinine; $\mathrm{P}<0.001$; Fig. 7). However, there was no significant difference in urinary sTim-3 concentrations between patients with SCR and AR (P=0.72; Fig. 7).

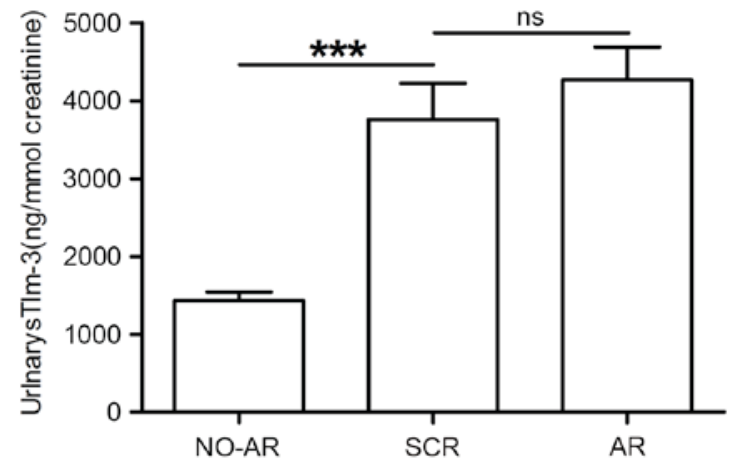

Figure 7. Average concentration of urinary sTim-3 in renal transplant patients with SCR compared with urinary sTim-3 in patients with AR and NO-AR. ${ }^{n s} \mathrm{P}>0.05$ and ${ }^{* * *} \mathrm{P}<0.001$, with comparisons indicated by lines. sTim-3, soluble T-cell immunoglobulin and mucin domain-containing protein 3; SCR, subclinical rejection; AR, acute rejection; NO-AR, no acute rejection.

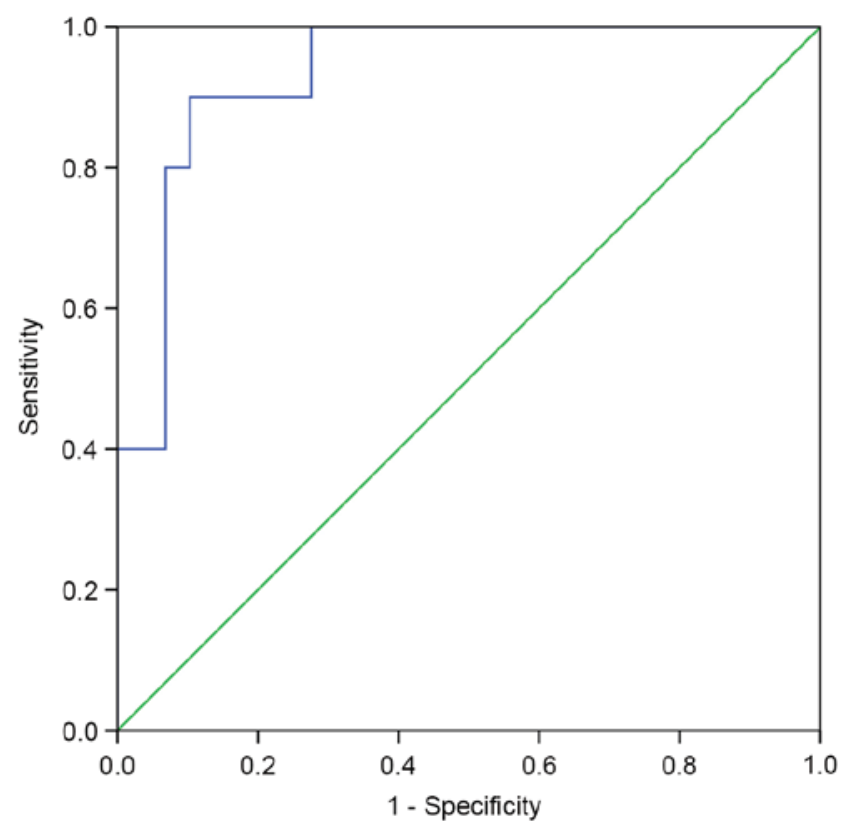

Figure 8. ROC curve analysis of urinary sTim-3 as a marker for the diagnosis of subclinical rejection. The area under the ROC curve was 0.858 (95\% CI: 0.738-0.978; $\mathrm{P}<0.001$ ), which demonstrated that sTim-3 was a suitable marker for the diagnosis of subclinical rejection. ROC, receiver operating characteristic; sTim-3, soluble T-cell immunoglobulin and mucin domain-containing protein 3.

A ROC curve was used to present the sensitivity and specificity of urinary sTim-3 levels as an indicator of SCR (Fig. 8). The area under the ROC curve was 0.934 (95\% CI: 0.87-0.99; $\mathrm{P}<0.001)$. The cutoff point that maximized the combined sensitivity and specificity for sTim-3 was $1,857 \mathrm{ng} / \mathrm{mmol}$ creatinine. At this threshold, the corresponding sensitivity and specificity was 90 and $82.8 \%$, respectively $(\mathrm{P}<0.001)$.

\section{Discussion}

To the best of our knowledge, this is the first time it has been demonstrated that the level of sTim-3 in urine may predict the incidence of AR and the response to anti-rejection therapy. Despite progress in immune suppression, acute allograft rejection remains one of the biggest obstacles in renal 
transplantation. At present, core needle biopsy represents the most reliable method to diagnose renal allograft rejection, although it is an invasive procedure with potential associated complications for the graft and the patient. Furthermore, once AR has been confirmed by biopsy, it is still difficult to predict therapeutic response accurately (12). It would be desirable to use a noninvasive technique tominimize the frequency of using biopsy for the diagnosis of acute rejection and to predict therapeutic response as much as possible. Some studies have identified some cytokines, such as adhesion molecules and chemokines (8), and reported that utilizing these cytokines is of great value in the treatment of renal allograft recipients $(11,12)$.

Tim-3 is exclusively expressed on the cell surface of fully differentiated $\mathrm{CD} 4^{+} \mathrm{Th} 1$ cells (14). The membrane bound form of Tim-3 includes an N-terminal immunoglobulin $\mathrm{V}$ domain, a mucin domain followed by a transmembrane domain and a short cytoplasmic tail. Although the soluble form (a splice variant) of Tim-3 lacks both the mucin and transmembrane domains, it still possesses the binding specificity of the membrane-bound form. Galectin-9 has been identified as a ligand for Tim-3; specific binding cross-talk between galectin- 9 and Tim-3 causes an inhibitory signal, resulting in apoptosis of Th1 cells and negatively regulated Th1 type immunity (16). Previous studies have also revealed that Tim-3 may participate in tolerance induction, and blockade of this molecule exacerbates experimental autoimmune encephalomyelitis as well as disease in the non-obese diabetic model of Type I diabetes $(16,17)$. In studies using galectin-9 to modulate Tim-3 activity, the rejection of fully allogeneic skin grafts was remarkably delayed, by up to 6 days, in mice receiving galectin-9 (22). Furthermore, in another experimental model, Tim-3 blockage resulted in abrogation of tolerance induction by costimulation blockage (17). A preliminary study also suggested that urinary Tim-3 mRNA is highly expressed in renal acute rejection (23). However, to the best of our knowledge, there are no data concerning the urinary sTim-3 in acute renal allograft rejection to date.

In the present study, a significant difference was discovered in the urinary excretion of sTim-3 between patients with NO-AR and those with AR or ATN. Patients with NO-AR displayed a relatively steady level of sTim-3, which generated no significant difference in the urine at during the early period ( 8 weeks) following transplantation. In view of the phenomenon that the level of urinary sTim-3 changed along with the occurrence of AR, sTim-3 might be a promisingly suitable marker to monitor renal function following transplantation. By non-invasive measurement of urinary sTim-3 levels, AR could be easily differentiated from ATN, and would be a preferred method compared with total urinary protein (24-27). Furthermore, high levels of urinary sTim-3 might effectively predict SRAR and graft loss. The urinary sTim-3 levels in patients with SRAR had significantly higher urinary sTim-3 concentrations than those with SSAR. While a cutoff point of urinary sTim-3 concentration was set at 3,242.9 $\mathrm{ng} / \mathrm{mmol}$ creatinine, the sensitivity and specificity for the diagnosis of SRAR reached 83.9 and $88.9 \%$, respectively. Achieving a more appropriate therapy by utilizing these results at an early stage following AR may effectively helped to prevent the further deterioration of immune injury, as well as to avoid the side-effects of high-dose steroid treatment. Furthermore, patients with subclinical rejection (SCR) were also demonstrated to excrete a significantly higher level of urinary sTim-3 than patients with NO-AR. At a urinary sTim-3 concentration of $1,857 \mathrm{ng} / \mathrm{mmol}$ creatinine, the sensitivity and specificity for the diagnosis of SCR was 90 and $82.8 \%$, respectively. Therefore, by means of measuring the level of urinary sTim-3, the probable immune state of the patients following renal transplantation can potentially be easily assessed and predicted. These results, of higher levels of the potential Th1-regulatory molecule sTim-3 in patients with AR or SCR, indicate that sTim-3 might competitively bind to the ligand of Tim-3 with fTim-3, which may reduce the binding of fTim-3 with the ligand of Tim-3, resulting in reduced Th1 cell apoptosis and positive regulation of the general immune status toward Th1 type. However, the diagnostic and predictive value of urinary Tim-3 needs to be verified in prospective multicenter studies. Further studies are warranted to confirm this association and to investigate the underlying mechanism.

In conclusion, the monitoring of sTim-3 in urine may be a novel and promising non-invasive approach for the detection of AR. Furthermore, measurement of sTim-3 in urine may contribute to predict the response to anti-rejection therapy and a poor outcome following AR. Likewise, other common causes of renal dysfunction, including polyoma virus nephritis, urinary infections and nephrotoxicity, should also be investigated prior to it becoming a non-invasive diagnostic test.

\section{Acknowledgements}

The study was supported by research grants from the Projects of Medical and Health Technology Development Program in Zhejiang province, (grant no. 2014KYA057) and the Foundation of Zhejiang Provincial Natural Science Foundation of China (grant no. LQ16H050003).

\section{References}

1. Curtis JJ: End-stage renal disease patients: Referral for transplantation. J Am Soc Nephrol 9 (12 Suppl): S137-S140, 1998.

2. Karam VH, Gasquet I, Delvart V, Hiesse C, Dorent R, Danet C, Samuel D, Charpentier B, Gandjbakhch I, Bismuth H and Castaing D: Quality of life in adult survivors beyond 10 years after liver, kidney and heart transplantation. Transplantation 76: 1699-1704, 2003.

3. Hariharan S, Johnson CP, Bresnahan BA, Taranto SE, McIntosh MJ and Stablein D: Improved graft survival after renal transplantation in the United States, 1988 to 1996. N Engl J Med 342: 605-612, 2000.

4. Meier-Kriesche HU, Schold JD, Srinivas TR and Kaplan B: Lack of improvement in renal allograft survival despite a marked decrease in acute rejection rates over the most recent era. Am J Transplant 4: 378-383, 2004.

5. Beckingham IJ, Nicholson ML and Bell PR: Analysis of factors associated with complications following renal transplant needle core biopsy. Br Urol 73: 13-15, 1994.

6. Thongboonkerd V, Mcleish KR, Arthur JM and Klein JB: Proteomic analysis of normal human urinary proteins isolated by acetone precipitation or ultracentrifugation. Kidney Int 62: 1461-1469, 2002.

7. Pieper R, Gatlin CL, Mcgrath AM, Makusky AJ, Mondal M, Seonarain M, Field E, Schatz CR, Estock MA, Ahmed N, et al: Characterization of the human urinary proteome: A method for high-resolution display of urinary proteins on two-dimensional electrophoresis gels with a yield of nearly 1400 distinct protein spots. Proteomics 4: 1159-1174, 2004. 
8. Hauser IA, Spiegler S, Kiss E, Gauer S, Sichler O, Scheuermann EH, Ackermann H, Pfeilschifter JM, Geiger H, Gröne HJ and Radeke HH: Prediction of acute renal allograft rejection by urinary monokine induced by IFN-gamma (MIG). J Am Soc Nephrol 16: 1849-1858, 2005.

9. Muthukumar T, Dadhania D, Ding R, Snopkowski C, Naqvi R, Lee JB, Hartono C, Li B, Sharma VK, Seshan SV, et al: Messenger RNA for FOXP3 in the urine of renal-allograft recipients. N Engl J Med 353: 2342-2351, 2005.

10. O'Riordan E, Orlova TN, Mei JJ, Butt K, Chander PM, Rahman S, Mya M, Hu R, Momin J, Eng EW, et al: Bioinformatic analysis of the urine proteome of acute allograft rejection. J Am Soc Nephrol 15: 3240-3248, 2004.

11. Peng W, Chen J, Jiang Y, Wu J, Shou Z, He Q, Wang Y, Chen Y and Wang $\mathrm{H}$ : Urinary fractalkine is a marker of acute rejection. Kidney Int 74: 1454-1460, 2008.

12. Peng W, Chen J, Jiang Y, Shou Z, Chen Y and Wang H: Acute renal allograft rejection is associated with increased levels of vascular endothelial growth factor in the urine. Nephrology (Carlton) 13: 73-79, 2008

13. D'elios MM, Josien R, Manghetti M, Amedei A, de Carli M, Cuturi MC, Blancho G, Buzelin F, del Prete G and Soulillou JP: Predominant Th1 cell infiltration in acute rejection episodes of human kidney grafts. Kidney Int 51: 1876-1884, 1997.

14. Monney L, Sabatos CA, Gaglia JL, Ryu A, Waldner H, Chernova T, Manning S, Greenfield EA, Coyle AJ, Sobel RA, et al: Th-1 specific cell surface protein TIM-3 regulates macrophage activation and severity of an autoimmune disease. Nature 415 536-541, 2002

15. Kuchroo VK, Umetsu DT, DeKruyff RH and Freeman GJ: The TIM gene family: Emerging roles in immunity and disease. Nat Rev Immunol 3: 454-462, 2003.

16. Sabatos CA, Chakravarti S, Cha E, Schubart A, Sánchez-Fueyo A Zheng XX, Coyle AJ, Strom TB, Freeman GJ and Kuchroo VK: Interaction of Tim-3 and Tim-3 ligand regulates T helper type 1 responses and induction of peripheral tolerance. Nat Immunol 4 1102-1110, 2003

17. Sánchez-Fueyo A, Tian J, Picarella D, Domenig C, Zheng XX, Sabatos CA, Manlongat N, Bender O, Kamradt T, Kuchroo VK, et al: TIM-3 inhibits T helper type 1-mediated auto- and alloimmune responses and promotes immunological tolerance. Nat Immunol 4: 1093-1101, 2003.
18. Khademi M, Illés Z, Gielen AW, Marta M, Takazawa N, BaecherAllan C, Brundin L, Hannerz J, Martin C, Harris RA, et al: T cell Ig- and mucin-domain-containing molecule-3 (TIM-3) and tim-1 molecules are differentially expressed on human Th1 and Th2 cells and in cerebrospinal fluid-derived mononuclear cells in multiple screrosis. J Immunol 172: 7169-7176, 2004.

19. Wu JY, Chen JH, Wang YM, He Q and Wu DB: Improved clinical outcomes in Chinese renal allograft recipients receiving lower dose immunosuppressants. Transplantation 78: 713-718, 2004.

20. Racusen LC, Solez K, Colvin RB, Bonsib SM, Castro MC, Cavallo T, Croker BP, Demetris AJ, Drachenberg CB, Fogo AB, et al: The Banff 97 working classification of renal allograft pathology. Kidney Int 55: 713-723, 1999.

21. Racusen LC, Colvin RB, Solez K, Mihatsch MJ, Halloran PF, Campbell PM, Cecka MJ, Cosyns JP, Demetris AJ, Fishbein MC, et al: Antibody-mediated rejection criteria-an addition to the Banff 97 classification of renal allograft rejection. Am J Transplant 3: 708-714, 2003.

22. Wang F, He W, Yuan J, Wu K, Zhou H, Zhang W and Chen ZK: Activation of Tim-3-Galectin-9 pathway improves survival of fully allogeneic skin grafts. Transpl Immunol 19: 12-29, 2008.

23. Renesto PG, Ponciano VC, Cenedeze MA, Saraiva Câmara NO and Pacheco-Silva A: High expression of Tim-3 mRNA in urinary cells from kidney transplant recipients with acute rejection. Am J Transplant 7: 1661-1665, 2007.

24. Escobedo-Villarreal MM, Mercado-Moreira AB, MuñozEspinosa LE, Gamboa-Esparza M, Pérez-Rodríguez E and Cordero-Pérez P: Urinary protein detection by iTRAQÒ associated with renal transplant complications and its modification with therapy. Cir Cir 83: 393-401, 2015.

25. Ghys LF, Paepe D, Taffin ER, Vandermeulen E, Duchateau L, Smets PM, Delanghe J and Daminet S: Serum and urinary cystatin $\mathrm{C}$ in cats with feline immunodeficiency virus infection and cats with hyperthyroidism. J Feline Med Surg 18: 658-665, 2016.

26. Yamada T, Arakawa Y, Mii A, Kashiwagi T, Kaneko T, Utsumi K, Masuda Y, Shimizu A, Iino Y and Katayama Y: A case of monoclonal immunoglobulin G1-lambda deposition associated with membranous feature in a patient with hepatitis $\mathrm{C}$ viral infection. Clin Exp Nephrol 16: 468-472, 2012.

27. Mäkelä S, Mustonen J, Ala-Houhala I, Hurme M, Koivisto AM, Vaheri A and Pasternack A: Urinary excretion of interleukin-6 correlates with proteinuria in acute Puumala hantavirus-induced nephritis. Am J Kidney Dis 43: 809-816, 2004. 